\title{
Investigation of Home Type Heliostat Systems Daylighting Performance with Lighting Simulation Software
}

\author{
E. Uygun ${ }^{1 \star}(\mathbb{D})$ and, S. Görgülü² (D) \\ ${ }^{1 \star}$ Suleyman Demirel University, Department of Civil Engineering, 32260, Isparta, Turkey. (e-mail: mail@emreuygun.com). \\ $\mathbf{2}$ Burdur Mehmet Akif Ersoy University, Dep. of Electrical - Electronics Eng., Burdur, Turkey. (e-mail: sgorgulu@mehmetakif.edu.tr).
}

\section{ARTICLE INFO}

Received: March.,09.2021

Revised: Apr.,1.2021

Accepted: Apr.,12.2021

Keywords:

Sustainability

Daylighting

DIALux

Heliostat

Solar architecture

Corresponding author: Emre Uygun

ISSN: 2536-5010 | e-ISSN: 2536-5134

\section{ABSTRACT}

Solar energy, which is an unlimited, costless and clean type of energy, is often preferred in architecture also as in all other areas. Today, all new technologies are made by focusing on solar energy. The main objective of lighting design in buildings is, to minimize energy consumption by keeping health and visual comfort at a high level. In this study, a home type heliostat system which is one of the modern and economic heliostat systems was introduced and its properties are listed. Based on the features of home type heliostat systems, all components of the system are modelled in a 3 Dimension stereolithography format. The daylighting performance of the home type heliostat systems was observed with the lighting simulation software. DIALux lighting design software was used in the study.

The results show that the home type heliostat systems can successfully transfer natural light into the building in a simulation environment created by modelling and contribute to illuminance.

DOI: https://doi.org/10.36222/ejt.893985

\section{INTRODUCTION}

Like every other area, energy consumption continues to increase its importance every day in all interior design. Keeping building performance at the top level has become a primary objective when lowering energy consumption. With the research and the developing technology, sustainability has also been commemorated with other terms such as green, ecological, user, and environmentally friendly [1]. With these concepts desired in the field of lighting, energy optimization should be achieved by not reducing the comfort of the room but by creating the necessary illuminance without compromising building performance and user health [2]. Besides these, the efficiently designed natural lighting system supports the balancing of the space, the heat loads, the health, and the activities of the users [3]. Today, about $20 \%$ of the electricity consumed is on a large part of the lighting needs [4]. Daylight has a very important place among renewable energies in terms of reducing electricity consumption around the world [5, 6]. Daylight gain in buildings has a very important position in terms of both heating and lighting.
The natural lighting provides to the desired area by taking maximum advantage of daylight in daylight time and minimizes energy consumption by artificial lighting or even completely remove it. Besides, the positive effects of natural daylight on people have been discussed in previous studies [7, 8]. The vast majority of people who live in the city spend daylight hours under artificial lighting without seeing the daylight, and the harmful effects of this have been explored in previous studies [9]. $80 \%$ of human perception capacity is realized with the sense of sight [10]. Therefore, healthy sensing can be realized with natural and optimum illumination. In another study on lighting, results were obtained by neurobiological studies [11]. As a result of this comprehensive study, it has been mentioned that healthy lighting affects the regulation of brain activities and affects the regulation of the melatonin hormone secreted by the body [12, 13]. When designing living space, designers must account for the fact that lighting design affects autonomic reactions, hormones, and our nervous systems [14]. In a study conducted by Innovative Design, daylight schools were established through sensors, as result of this study, because of this space 
which can use daylight in every area it was observed that the rate of children's coming to school was increased, there was a great reduction in library volume and children were much cheerful and they showed a rapid development [15]. In line with the work done, natural energy recovery and lighting design are at the forefront when the general methods are insufficient to provide the required lighting levels. In the design stage of the place, this situation should be determined and calculated by various simulation software. Alternative methods have emerged for current buildings and new buildings without energy-saving calculations at the design stage [16]. Because of the mini software and sensors, heliostat systems that collect and concentrate daylight are used in lighting systems from the past to the present [17]. Despite the rapid development of artificial lighting technologies designers are directed to the use of natural resources together with artificial lighting [18]. It has been realized that the energysaving potential of the buildings can be subtracted to the upper levels with natural lighting [19]. With the correct use of a natural source such as the sun at our disposal, CIE lighting standards and optimum illuminance can be reached. Because of the building's north direction, it may not have access to daylight and environmental factors which block daylight can also cause this [20]. Home type heliostat systems can be used in these types of variations and even to remove frosted areas. The sun, which plays a major role in sustainable architecture in particular, plays a major role in optimizing energy use [21]. The importance of solar energy in energy-efficient buildings has been mentioned in earlier studies. In these studies, the importance of transferring daylight into living space and direct and indirect lighting methods are mentioned. It has been observed that energy consumption can be reduced between $30 \%$ and $70 \%$ by using natural lighting in addition to artificial lighting [22].

This study aimed to observe the value of daylight that home type heliostat systems can transfer into the building in a simulation environment, to present the obtained data with graphics, and to create a sample study with DIALux software for future studies.

\section{MATERIAL AND METHODS}

The home type heliostat system used in simulation has motors that provide 2-axis motion. Includes one sun sensor to detect and track the sun and it has one microprocessor that determines the motion by processing this data [23]. Provides the power of the movement with the solar energy collects by the solar panels located on it. Thus, there is no need for any external energy source to operate. It reflects daylight to the living space with its solar-powered motors and vinyl-coated reflectors. The light reflection area is about half a square meter and according to the manufacturer, the light stream is expected to correspond to 50,000 lumens or 500 watts [23]. This power is equivalent to approximately 60 standard light bulb luminous flux. First of all, the home type heliostat system has been detailed by plotting it as a technical drawing. The created a scaled format was transferred to the 3D modelling software by using the DXF (Drawing Interchange File) format. The 3D model of the home type heliostat system was created for the lighting design simulation process and visualization by utilizing the measurements on the picture. The modelled home type heliostat system is shown in Figure 1.

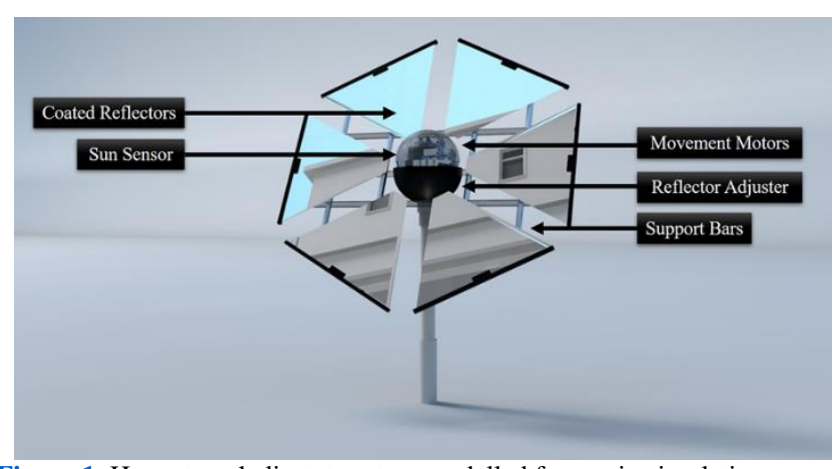

Figure 1. Home type heliostat system modelled for use in simulation

The modelling process was carried out by taking the basic information of the maximum height, the coating reflection rates, the axial rotation restrictions, and each component such as reflector number, reflector dimensions, electronic components, protection materials, axis support rods, sun sensor limits. A total of $160 \mathrm{~m}^{2} 2$-story villa has been modelled and prepared for the virtual simulation environment created. Illumination-focused windows are added and the entrance is positioned to be in the east direction. The model and simulation area view is shown in Figure 2. Coating, wall paints, window materials, reflecting rate information of the models has been entered in the DIALux software for the best results. Completed models were converted to 3D STL file format and exported from the 3D design software by object transfer to the lighting simulation area in DIALux. The distance of the home type heliostat system from its targeted space is planned as $9.1 \mathrm{~m}$ and the upper angle which it will make with vertical targeted as 160 and the lower angle targeted as 3o. This angle determined in daylight design is very important and the ideal angle range to be used year-round is shown between +15 and -15 degrees [24]. The distance and angle values determined for the home type heliostat system were selected according to the maximum dimensions determined by the manufacturers such as Wikoda [23, 24].

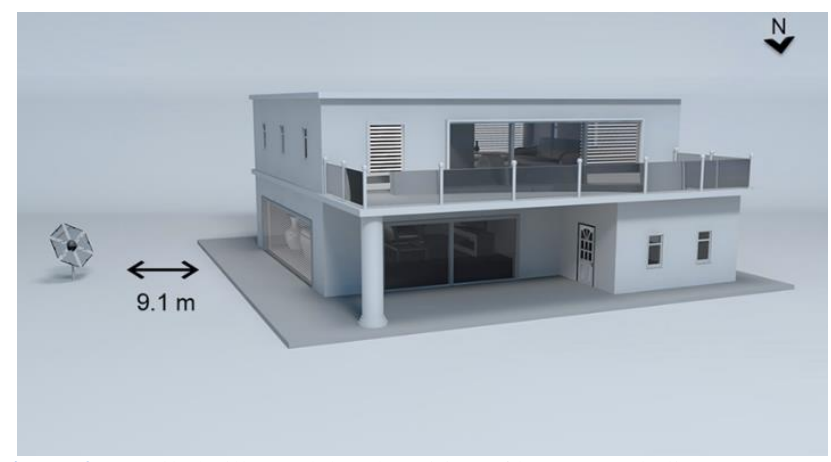

Figure 2. Detailed villa model and position of home type heliostat system

Information of the region where the simulation will be performed is defined in the software as 29.00 longitudes 41.00 latitude location in Turkey / Istanbul. Turkey is a good location for this type of application [25]. To make regular measurements throughout the day and to obtain optimal results, the definition of the time zone is Istanbul (UTC +02 : 00).

Interior walls, texture coatings, and reflection rates have been set following the standards for an optimal simulation. At the same time, interior detailing models of the building and other parts were made transferable passing through a structural arrangement in STL format as separate files. The transferred interior detail models were placed in the space. 
Texture coatings and reflection rates of the locally organized internal detail models were entered. Daylight calculation is performed using the three different sky models described in CIE 110-1994 in the DIALux lighting simulation software. These occur with the formation of sun position and light stage following the time zone and region of the software according to cloudy sky, average sky, and clear sky conditions. In the study conducted, modelling and daylight staging was performed using open sky conditions without a heliostat system and with a heliostat system at 1-hour intervals throughout the day. The open sky condition is chosen as the condition that can best measure heliostat efficiency from natural lighting methods. This system and similar ones have shown their true abilities when they are placed properly in the upper part of a window opening to capture the sky beam in open sky conditions and to direct their direct component to the part near the ceiling window [26, 27]. Polygon constructions of the used design materials were transferred to the DIALux software without distortion in their structural details by keeping their polygon structures at a detailed level and by maintaining scales while importing interior design models. Thus, in the daylight lighting simulations which will be made although the simulation and calculation times are extended, it is aimed to get the most accurate results from the simulation. Reflection rates of textures (wall, floor, furniture) are presented in Figure 3.

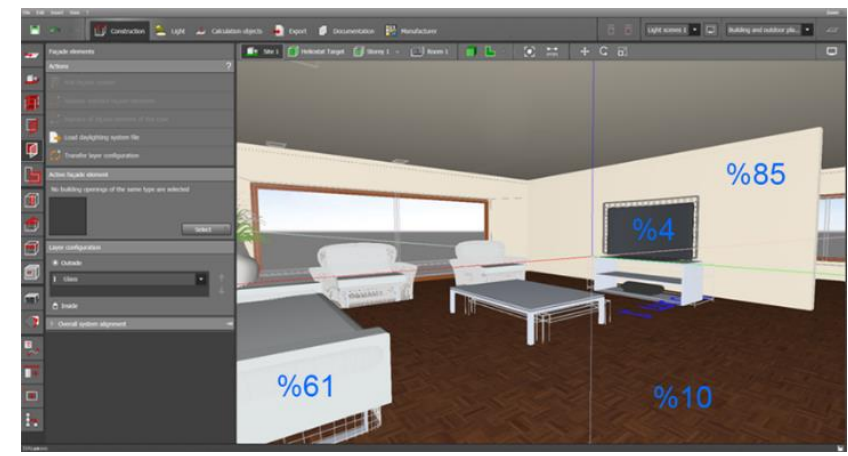

Figure 3. Reflection rates of textures

Calculation area 1 (daylight transfer area which is the primary target of the home type heliostat system), calculation area 2 (Interior zone at the working plane defined by the DIALux software) were defined. Then the two defined areas were simulated model together with the open sky by measurements made at intervals of one hour per day. In the DIALux lighting simulation software, according to sun position, the home type heliostat system repositioned with hourly metrics by calculating angle with measurement horizontally for best results. Solar track sensor section, support section, and reflective surfaces were separately defined to DIALux lighting simulation software and therefore this positioning was made possible. The angular adjustment of the reflective surfaces is shown in Figure 4. Defined angular movement and the angle required for the home type heliostat system to the specified targets are determined by the NOAA (Earth System Research Laboratory) solar calculator. Angular changes of less than $1^{\circ}$ were entered by using object position in the DIALux software [28]. The working plane and window, defined as the target for the home type heliostat system, were used as virtual computing fields to obtain daylight illumination values.

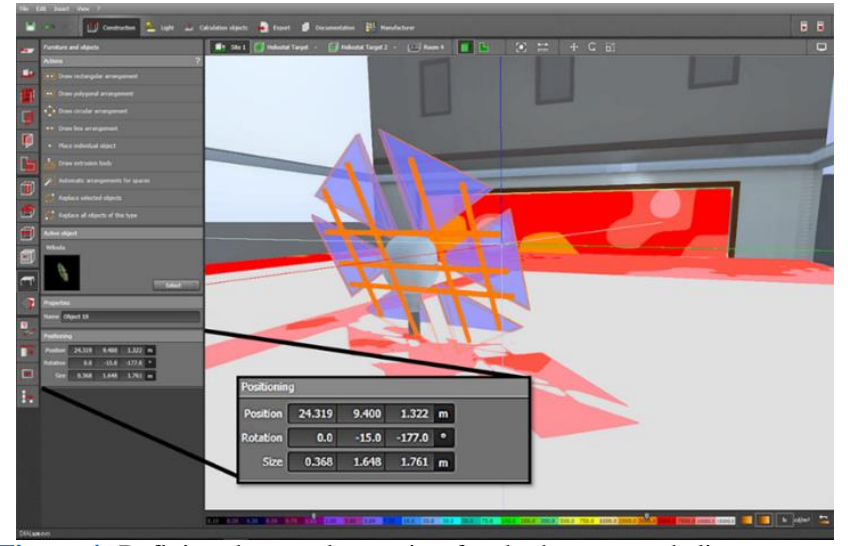

Figure 4. Defining the angular motion for the home type heliostat system reflective surfaces

When the amount of solar energy transfer used in the windows decreases, the light transmission also decreases [29]. The window glasses used in the modelled space were defined in standard single glass properties at a rate of $90 \%$ permeability. The preliminary comparison image of the home type heliostat system position calculations at the same time and conditions is presented in Figure 5. Afterwards, results were obtained with the home type heliostat system at intervals of one hour throughout the day and the contribution rate of the heliostat model to illuminance was calculated to be compared with the tables.

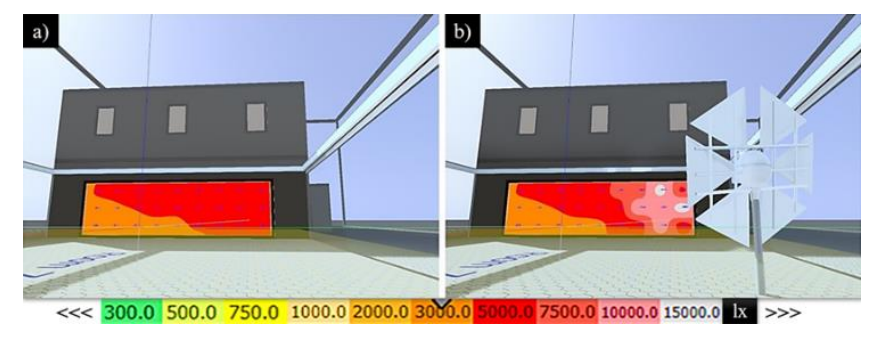

Figure 5. Sample images are taken from daylighting simulation under equal conditions (a) Without home type heliostat (b) With home type heliostat

\section{RESULTS AND DISCUSSION}

For the measurement which its modelling and simulation preliminary information is completed, the indoor working plane which was defined by DIALux software has two different virtual measurement surfaces as indicated in Figure 7 , windows are set as light zones of brightness levels. These zones were established for taking a total of 12 results hourly in open sky conditions between 07:00 a.m. and 06:00 p.m. on 01.06.2017. The graph of the colour information graph values based on DIALux software data is shown in Figure 6. According to this data, the first contact points of the daylight are measured at 15,000 lux and more. These points are represented by a white tissue sample. The daylight-gathering criterion is distributed in the hot-cold colour range.

\footnotetext{
Figure 6. The colour range of DIALux lighting software illuminance

Daylight transferring element (window) and working plane (living space) which are 2 calculation areas was specified in DIALux software. The measurements taken from these areas are presented in comparison tables. The images of these 2 calculation areas are shown in Figure 7.
} 

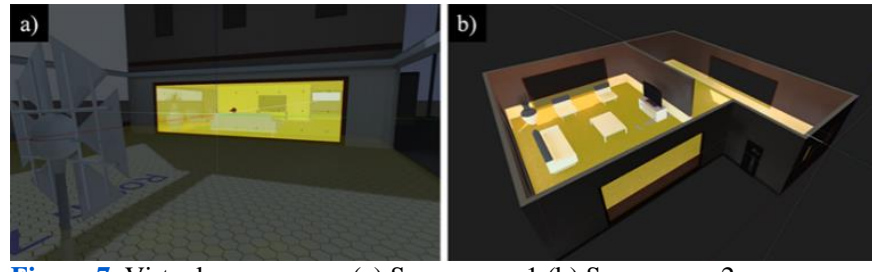

Figure 7. Virtual sensor areas (a) Sensor area 1 (b) Sensor area 2

Virtual illumination level sensors are placed on the window (virtual sensor area 1) and the work plane (virtual sensor area 2). Dimensions of the measuring areas serving as sensors were determined as $6.1 \times 2.2 \mathrm{~m}$ and $8.4 \times 9.5 \mathrm{~m}$, respectively. Measurements were taken on equal conditions, every 1 -hour interval in the 2 defined calculation areas, and binary comparison tables were generated from the obtained data. Based on the results of the calculation area data comparison given in Tables 1 and 2, comparisons were made by drawing a table of illumination intensity change charts.

TABLE 1

MAXIMUM ILLUMINANCE OBTAINED THROUGH THE WINDOW (AREA 1)

\begin{tabular}{ccc}
\hline \hline Clear sky & \multicolumn{2}{c}{ Calculation area 1 } \\
\hline $\begin{array}{c}\text { Date / Time } \\
(01.06 .2017)\end{array}$ & Heliostat passive & Heliostat active \\
\hline $07: 00$ & $22,3781 \mathrm{x}$ & $22,631 \mathrm{~lx}$ \\
\hline $08: 00$ & $47,196 \mathrm{~lx}$ & $47,456 \mathrm{~lx}$ \\
\hline $09: 00$ & $57,417 \mathrm{~lx}$ & $57,706 \mathrm{~lx}$ \\
\hline $10: 00$ & $56,197 \mathrm{~lx}$ & $56,531 \mathrm{~lx}$ \\
\hline $11: 00$ & $46,298 \mathrm{~lx}$ & $46,6251 \mathrm{x}$ \\
\hline $12: 00$ & $30,7681 \mathrm{x}$ & $30,913 \mathrm{~lx}$ \\
\hline $13: 00$ & $11,8351 \mathrm{x}$ & $12.727 \mathrm{~lx}$ \\
\hline $14: 00$ & $7,6461 \mathrm{x}$ & $8,7841 \mathrm{x}$ \\
\hline $15: 00$ & $5,411 \mathrm{~lx}$ & $7,0741 \mathrm{x}$ \\
\hline $16: 00$ & $4,3251 \mathrm{x}$ & $5,7351 \mathrm{x}$ \\
\hline $17: 00$ & $3,2161 \mathrm{x}$ & $3,9701 \mathrm{x}$ \\
\hline $18: 00$ & $3,0761 \mathrm{x}$ & $3,4321 \mathrm{x}$ \\
\hline \hline
\end{tabular}

TABLE 2

MAXIMUM ILLUMINANCE OBTAINED OVER THE WORKING PLANE (AREA 2)

\begin{tabular}{ccc}
\hline \hline Clear sky & \multicolumn{2}{c}{ Calculation area 2 } \\
\hline $\begin{array}{c}\text { Date / Time } \\
(01.06 .2017)\end{array}$ & Heliostat passive & Heliostat active \\
\hline $07: 00$ & $4,2381 \mathrm{x}$ & $4,303 \mathrm{~lx}$ \\
\hline $08: 00$ & $6,953 \mathrm{~lx}$ & $7,028 \mathrm{~lx}$ \\
\hline $09: 00$ & $7,765 \mathrm{~lx}$ & $7,854 \mathrm{~lx}$ \\
\hline $10: 00$ & $7,2401 \mathrm{x}$ & $7,335 \mathrm{~lx}$ \\
\hline $11: 00$ & $5,840 \mathrm{~lx}$ & $5,945 \mathrm{~lx}$ \\
\hline $12: 00$ & $4,048 \mathrm{~lx}$ & $4,162 \mathrm{~lx}$ \\
\hline $13: 00$ & $2,8451 \mathrm{x}$ & $2,984 \mathrm{~lx}$ \\
\hline $14: 00$ & $2,2581 \mathrm{x}$ & $2,4201 \mathrm{x}$ \\
\hline $15: 00$ & $1,971 \mathrm{~lx}$ & $2,1581 \mathrm{x}$ \\
\hline $16: 00$ & $1,844 \mathrm{~lx}$ & $2,0401 \mathrm{x}$ \\
\hline $17: 00$ & $1,741 \mathrm{~lx}$ & $1,9551 \mathrm{x}$ \\
\hline $18: 00$ & $1,5891 \mathrm{x}$ & $1,7991 \mathrm{x}$ \\
\hline \hline
\end{tabular}

According to the data taken for these zones, it is seen that the average home type heliostat system effect for the working plane is around an average of 150 lux. A gain zone chart was given for workspace values in the direction of the data which is obtained with DIALux software and presented in Table 2. Figure 8 shows a graph of the average value of the gain for the working plane (Area 2) generated from the obtained data.

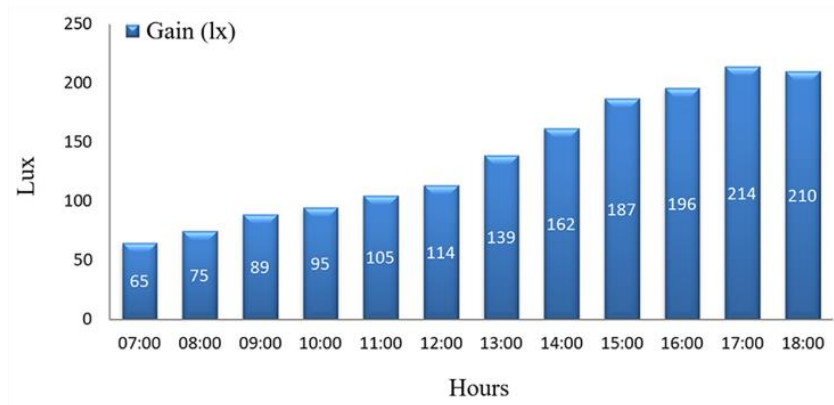

Figure 8. Working plane average lighting gain chart with home type heliostat system

Observed that in the simulation area created, home type heliostat system has been observed that it contributes totally up to 1,000 lux between 12:00 p.m. - 06:00 p.m. It was observed that the home type heliostat systems had a contribution of $3.41 \%$ in total to the working plane luminous intensity when the daylight is active. The visualization of these values as a color distribution in the DIALux software is presented in Figure 9.

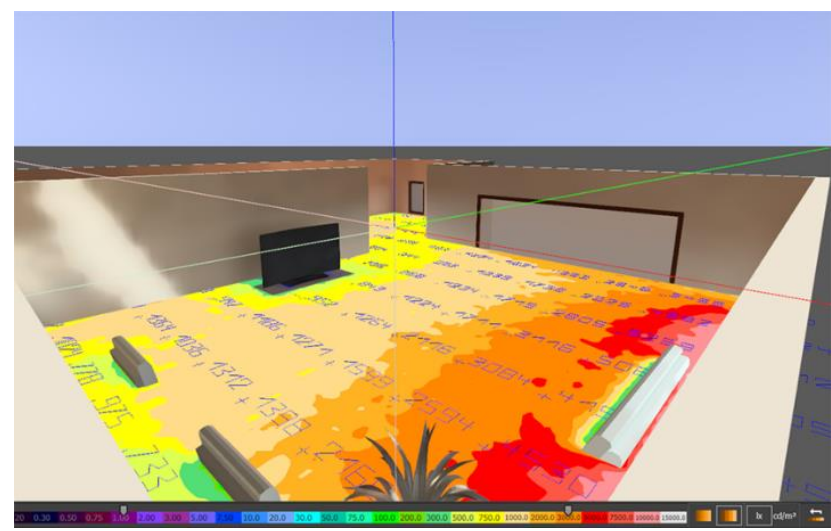

Figure 9. Illuminance colour distribution at the working plane (area 2)

Luminous distribution and brightness values at the $15 \mathrm{~m}^{2}$ walls where daylight is projected by using the home type heliostat system are presented in Figure 10.

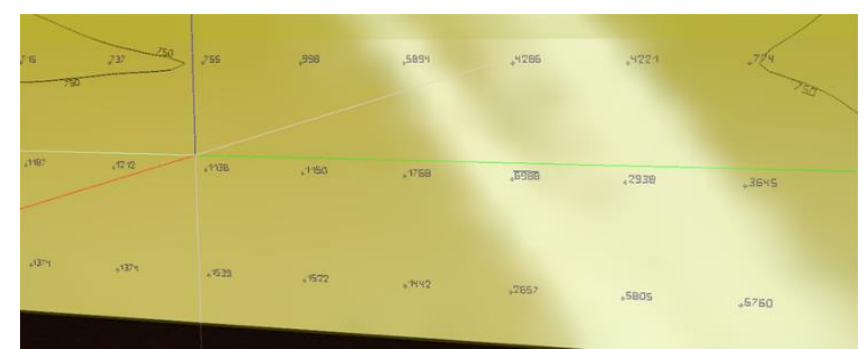

Figure 10. Image of the luminous distribution and brightness values from wall

According to the measurements taken from the working plane (Area 2), it has been observed that the home type heliostat system can instantaneously add up to $200 \mathrm{~lx}$ value to the average illuminance. The positioning of these systems in 
the design phase of the challenging spaces can provide great advantages to the designer. At the same time, this will help to create sustainable buildings that conserve energy. The use of such natural energy resources, which can create a visual unity with space, will become an indispensable part of modern architecture and eco-friendly places. The architectural visualization of the system modeled as a simulation area is given in Figure 11.

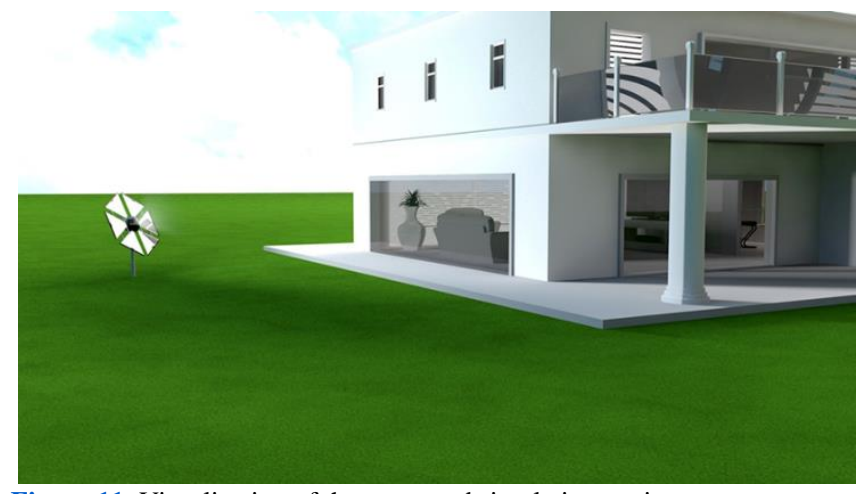

Figure 11. Visualization of the generated simulation environment

Thanks to the reflective ratio coating feature of the DIALux software, the positive effect of home type heliostat systems on sustainable structures can be observed in the simulation environment. This observation will also give an advantage to the designer and with the use of preliminary calculations of such systems in further studies, will be reflected as positive effects on nature, humans, space, and the environment. Because of the easy-to-use feature of home type heliostat systems, more efficient hybrid systems can be found by investigating the possibility of simultaneous operation with other systems which are difficult to integrate into living areas [30]. As we know it, such systems use the sun as a light source, that's why it will be beneficial to use them for the areas which have high daylight-taking time. With the use of the north facade of the place, the heating problem caused by the transfer can be overcome. Regions such as Turkey have an effective geographical settlement with their location for lighting systems that utilize natural energy [31]. The natural daylight reaching indoors will be beneficial to our physique balance system in the first place. This type of natural lighting application will help people to improve their health and productivity levels by reducing stress levels. Thanks to daylight transmitted by natural lighting systems, they will provide physiologically positive effects to us. Also, in geographically disadvantaged areas, for example, it has been observed that in deep valleys, there is a system that can contribute to lighting values in shaded facades of places located on steep slopes. The use of such systems in conjunction with artificial lighting systems may provide maximum electricity savings by reducing the duration of artificial lighting devices. This study will be a reference to future research in terms of simulation and measurement methods for home type heliostat systems.

\section{CONCLUSION}

According to the manufacturers, light stream from home type heliostats is expected to correspond to 50,000 lumens and the illuminance for a $0.5 \mathrm{~m}^{2}$ area transmitted from the recommended $9.1 \mathrm{~m}$ distance is an average of 15,000 $\mathrm{lx}$ and above $[23,24,32]$. This value was observed and visualized in the lighting simulation. In the measurements taken from the working plane, it has been observed that the home type heliostat system can instantaneously add up to $200 \mathrm{~lx}$ to the average illuminance. These systems, which are practical for installation and application, are introduced for the alternative lighting methods, and simulation data was generated for the home type heliostat systems in the name of sustainable buildings.

\section{ACKNOWLEDGEMENT}

This study has been produced from the master's degree dissertation of Emre UYGUN.

\section{REFERENCES}

[1] B. Edwards, E. Naboni. "Green buildings pay: Design, productivity and ecology", London, 2013.

[2] V. Loftness, B. Hakkinen, O. Adan, A. Nevalainen. "Elements that contribute to healthy building design", Environmental Health

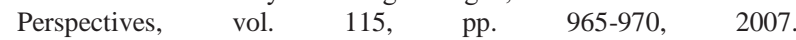
https://doi.org/10.1289/ehp.8988

[3] I.G. Capeluto. "The influence of the urban environment on the availability of daylighting in office buildings in Israel", Building and Environment, vol. $38, \quad$ pp. 745-752, 2010. https://doi.org/10.1016/S0360-1323(02)00238-X.

[4] T. Rubeis, M. Muttillo, L. Pantoli, I. Nardi, I. Leone, V. Stornelli, D. Ambrosini. "A first approach to universal daylight and occupancy control system for any lamps: Simulated case in an academic classroom", Energy Buildings, vol. 152, pp. 24-39, 2017. https://doi.org/10.1016/j.enbuild.2017.07.025.

[5] U.S. Energy Information Administration (EIA), "Annual Energy Outlook", USA, 2012

[6] N. Nasrollahi, E. Shokri. "Daylight illuminance in urban environments for visual comfort and energy performance", Renewable and Sustainable Energy Reviews, vol. 66, pp. 861-874, 2016. https://doi.org/10.1016/j.rser.2016.08.052.

[7] F. M. Marks. "Letter to the Editors: Lighting for Different Healthcare Settings", Health Environments Research and Design Journal, vol. 6, no. 3, pp., 166-168, 2013. https://doi.org/10.1177\%2F193758671300600314.

[8] G.H. Lim, M.B. Hirning, N. Keumala, N.A. Ghafar. "Daylight performance and user's visual appraisal for green building offices in Malaysia", Energy and Building, vol. 141, pp. 175-185, 2017. https://doi.org/10.1016/j.enbuild.2017.02.028.

[9] E. Uygun, S. Görgülü. "Daylight simulation performance comparison of DIALux and RELUX Illumination simulation programs", The Journal of Graduate School of Natural and Applied Sciences of Mehmet Akif Ersoy University, vol. special no. 1, pp. 1-8, 2016.

[10] F. Çetin, B. Gümüş, Y. Özbudak. "Ergonomic evaluation of lighting characteristics", 2nd National Lighting Symposium and Exhibition, Diyarbakir, pp. 20-23, 2003.

[11] M.S. Rea. "Light-much more than vision, proceedings of light and human health: EPRI/LRO”, 5th International Lighting Symposium, Palo Alto, CA, pp. 1-15, 2002.

[12] P. Badia, B. Myers, M. Boecker, J. Culpepper, J.R. Harsh. "Bright light effects on body temperature, alertness, EEG and behavior", Physiology and Behavior, vol. 50, no. 3, pp. 583-588, 1991. https://doi.org/10.1016/0031-9384(91)90549-4.

[13] A.J. Lewy, T.A. Wehr, F.K. Goodwin, D.A. Newsome, S.P. Markey. "Light suppresses melatonin secretion in humans", Science, vol. 210, 1267-1269, 1980. https://doi.org/10.1126/science.7434030.

[14] W. Bommel. "CIE and the way of putting 'lighting and health' into daily lighting practice, Proceeding Book of Lux Europa", 10th European Lighting Conference, Berlin, pp. 25-26, 2005.

[15] B. Matusiak. "Daylight design for healthy learning environments", Professional Lighting Design, Turkey, vol. 33, pp. 72-76, 2010.

[16] U.S., Green Building Council, https://www.usgbc.org/credits/healthcare/v4-draft/eqc-0.

[17] S. Aydinl, A. Rosemann. "A new lighting scheme that combines natural and artificial lights with heliostats and light transmitters", 3rd National Lighting Congress, Istanbul, pp. 36-43, 2000.

[18] T. Yapar. "Energy Saving with Lighting Automation", Master Thesis, Yıldız Teknik University, Istanbul, 2007. 
[19] W.M. Lam. "Sunlighting as formgiver for architecture", New York, 1986.

[20] C. Willis. "Form Follows Finance: Skyscrapers and Skylines in New York and Chicago", Princeton Architectural Press, New York, 1995.

[21] M. Guzowski. "Daylighting for Sustainable Design", McGraw-Hill, USA, 2010

[22] İ. Yüksek, T.T. Karaday1. "Energy-Efficient building design in the context of building life cycle", Energy Efficient Buildings, 2017. https://doi.org/10.5772/66670.

[23] Wikoda, Natural sunlight to your home, http://wikoda.com.

[24] eSolar energy news, Wikoda, http://www.esolarenergynews.com/p/wikodas-sunflower.html.

[25] G. Z. Brown, M. Dekay. "Sun, Wind and Light: Architectural Design Strategies", John Willey and Sons Inc., USA, 222-223, 2001.

[26] Building Physics Expertise Applications, http://www.yfu.com/yazilar/mim65-mayis.pdf.

[27] B. Erel. "A research on new technologies developed in the field of lighting with natural daylight", Master Thesis, Istanbul Teknik University, Istanbul, 2004.

[28] NOAA, Solar Position Calculator, https://www.esrl.noaa.gov/gmd/grad/solcalc.

[29] G. E. Weidtman. "Considerations in the selection of solar energy controlled reflected glass in curtain wall”, Flachglas A. G. 1999.

[30] Z. Wang, Y.K. Tan. "Illumination control of LED systems based on neural network model and energy optimization algorithm”, Energy and Buildings, vol. 62, pp. 514-521, 2013. https://doi.org/10.1016/j.enbuild.2013.03.029.

[31] A. Sozen, E. Arcaklioglu, M. Ozalp, E. Kanit. "Solar-energy potential in Turkey", Applied Energy, vol. 80, no. 4, 367-381, 2005. https://doi.org/10.1016/j.apenergy.2004.06.001.

[32] Heliostat Design Concepts, http://www.redrok.com/concept.htm

\section{BIOGRAPHIES}

Emre Uygun received his bachelor's degree in Construction Education from Süleyman Demirel University in 2015. He received his master's degree in Spatial Planning and Design (Interdisciplinary) at Burdur Mehmet Akif Ersoy University in 2018. During his undergraduate and graduate studies, he worked at Süleyman Demirel Technopark for 5 years and actively took a part in TÜBİTAK projects covering the fields of health, nanotechnology, fiber lasers, materials and design. Moreover, he is studying another bachelor degree at the Isparta University of Applied Sciences, Department of Civil Engineering. Currently, he is a Ph.D. student in the Department of Sustainable Building Materials and Technologies within the scope of priority areas in the Civil Engineering Department of Süleyman Demirel University. He is awarded by scholarships of YÖK 100/2000 doctoral program and TUBITAK 2211$\mathrm{C}$ program for his $\mathrm{Ph} . \mathrm{D}$. thesis subject.

He has been involved in international studies in the fields of artificial intelligence, lighting design, sustainable building materials and technologies, nanotechnology, laboratory measurement and analysis techniques, transportation engineering. He has a patent submission for his Ph.D. project which focused on the application of artificial intelligence on a transportation system. He is currently working on a project developed in the field of smart railways and continues his doctorate education.

Sertaç Görgülü obtained his B.Sc. degree from Marmara University in 2001. In 2002, he started to work as a research assistant at Marmara University. He received his M.Sc. and Ph.D. degrees from Marmara University in 2004 and 2011 respectively. Between 2009 and 2013, he worked at Kirklareli University in various titles. He has been working at Burdur Mehmet Akif Ersoy University since 2013.

He works in the fields of natural and artificial lighting and design, renewable energy. 